\title{
Foundations of Supply Chain Management for Space Application
}

\author{
By Michael Galluzzi, NASA* \\ NASA Kennedy Space Center, Florida 32899 \\ Edgar Zapata, NASA' \\ NASA Kennedy Space Center, Florida 32899 \\ Martin Steele, Ph.D. NASA \\ NASA Kennedy Space Center, Florida 32899 \\ Olivier de Weck, Ph.D. ${ }^{\S}$ \\ Massachusetts Institute of Technology \\ 77 Massachusetts Ave,Cambridge, Massachusetts, 02139
}

Supply Chain Management (SCM) is a key piece of the framework for America's space technology investment as the National Aeronautics and Space Administration (NASA), the aerospace industry, and international partners embark on a bold new vision of human and robotic space exploration beyond LowEarth-Orbit (LEO). This type of investment is driven by the Agency's need for cost efficient operational support associated with, processing and operating space vehicles and address many of the biggest operational challenge including extremely tight funding profiles, seamless program-to-program transition activities and the reduction of the time gap with human spaceflight capabilities in the post-Shuttle era. An investment of this magnitude is a multiyear task and must include new patterns of thought within the engineering community to respect the importance of SCM and the integration of the material and information flow. Experience within the Department of Defense and commercial sectors which has shown that support cost reductions and or avoidances of upwards to $35 \%$ over business as usual are achievable. It is SCM that will ultimately bring the solar system within the economic sphere of our society.

Applying aspects of the high-volume, market demand driven SCM disciplines of the commercial industry to a low-volume, schedule driven aerospace environment is not only possible but vital to accurately estimate, plan, control and manage the non-recurring and recurring costs associated with long-term operations and vehicle processing of space flight and ground support equipment. Applying these disciplines is especially crucial during the early design, development, test and engineering (DDT\&E) phase of a new program. Upwards of 70 to $80 \%$ of the operational recurring costs, which include $90 \%$ of the indirect processing costs associated with Launch and Landing core activities, are influenced as a result of this initial phase of the product lifecycle. Breakthroughs in the commercial field of SCM are giving top-level commercial industry operations and production managers the forecasting and integration capability needed to create a just-intime and on-demand rapid mobilization of manufacturing sources.

Comparatively, as we turn our attention to very large space endeavors, delegation of sustainment activities from the Program to the Project Offices, complicates the integration and forecasting of material and information flows, and could prevent true integration from ever being achieved. Good collaborative forecasting, planning and realistic replenishment scheduling is essential to an effective SCM practice especially, when considering simultaneous non-serial activity of diverse new programs anticipated for future Lunar and Mars expeditions.

\footnotetext{
* Supply Chain / DMSMS Specialist, Space Shuttle Program Office, John F. Kennedy Space Center/MK-SSO

${ }^{\dagger}$ Technical Manager, Engineering Development Directorate, Systems Engineering and Integration Office, John F. Kennedy Space Center/DX-C

* Technical Manager, Engineering Development Directorate, Systems Engineering and Integration Office, John F. Kennedy Space Center/DX-C

$\S$ Assistant Professor, Aeronautics and Astronautics and Engineering Systems Division, Massachusetts Institute of Technology

-1 -

Presented at the AIAA Space 2006 Conference, San Jose, California

This material is declared a work of the U.S. Government and is not subject to copyright protection in the United States.
} 


\section{Acknowledgements}

This work was completed as part of the Explorations Systems Mission Directorate, Integrated Modeling and Simulation Group. Michael Galluzzi of NASA's Kennedy Space Center and Dr. Mansooreh Mollaghasemi of Productivity Apex, Inc., served as key investigators on the Earth-to-Orbit Modeling Simulation with Edgar Zapata from NASA's Kennedy Space Center as COTR. Additionally, the Interplanetary Supply Chain Management \& Logistics Architectures Project under contract NNKO5OA50C, Prof. Olivier de Weck and Prof. David Simchi-Levi, Massachusetts Institute of Technology, served as the principal investigators, with Dr. Martin Steele from NASA's Kennedy Space Center as COTR. Dr. Mohamed Fayez, Michael Callinan of Productivity Apex, were instrumental in providing valuable insight and feedback, as were Michael McClain, Scott Sealing from the United Space Alliance and Dan Swartwood of PRAGMATECK Consulting Gp, Inc. in defining Supply Chain Council "SCOR". We also thank Jack Molchany, Program Manager of Concurrent Technologies Corporation for providing new insight to the DLA-DoD B3i Program.

\section{Introduction}

In May of 2004, the Government Accounting Office sent a Report to the Subcommittee on Space and Aeronautics, Committee on Science, House of Representatives titled "NASA's lack of Disciplined Cost-estimating Processes Undermines NASA's Ability to Effectively Manage its Programs". This report recommended that NASA develop an integrated plan to, among other things, staff and support for cost-estimating and full cost management through Earned Value Management (EVM), which helps identify variances before they disrupt the program and ties directly to the 1996 Federal Financial Management Improvement Act (FFMIA). It also recommended establishing a standard framework for lifecycle cost estimates through use of a Cost Analysis Data Requirements (CADRe) model and to focus on the Agencies materials and Plant, Property and Equipment (PP\&E), which includes space flight and ground support equipment as well as infrastructure and facility assets. Before we can comment on NASA's cratered budgetary landscape and years of "Unqualified" or "Disclaim" opinion by the auditors, we must get a better understanding of PP\&E assets, how these assets came to be, how inventory assets are managed, how supplier and product-line viability can impact the cost estimating process and finally how SCM simulation and modeling can help in the future.

It is our hope that this paper will motivate the aerospace community in deploying the fundamentals of SCM along with simulation and modeling breakthroughs with the objective of growing a risk shared endeavor between customer and contractor, that utilizes an integrated and cost effective supply chain through collaborative demand planning, Component Supply Management (CSM), product standardization, rapid mobilization of consolidated manufacturing sources and SCM simulation and modeling. "Often times, a supply chain is thought of only in terms of Integrated Logistical Support (ILS), and within the ILS exists the need to sustain a viable supplier base. While this is an important and critical function for the success of any endeavor, ILS is better considered as an enabler to the entire supply chain rather than the supply chain itself, when that supply chain is defined in terms of the enterprise or program. In today's environment, the supply chain truly encompasses a much broader spectrum." A SCM process can be defined further as an integrated network of materials and information flow supporting a common hardware sparing and repair philosophy throughout a program for long-term support of space exploration. A NASA supply chain implementation brings the methodology needed for planning and executing:

1) The selection of flexible and reliable sources of supply during the entire system lifecycle

2) Agile manufacturing and procurement processes that can rapidly respond to unknown and changing elasticity in demand

3) Good collaborative probabilistic supply/demand forecasting in executable form with procedural representation of the processes

4) Key performance indicator metrics based on the Supply Chain Operations Reference Model (SCOR) and used to guide improvement investments.

"A driving force behind SCM is the recognition that suboptimization occurs if each organization in the supply chain attempts to optimize its own results rather than to integrate its goals and activities with other organizations to optimize the results of the chain." ${ }^{2}$ We are not implying a central, logistics architecture or Performance Based Logistics (PBL) concept but rather a re-definition of commercial SCM in the context of human space flight activities. Within the NASA and Aerospace community, the logistics of it, and it's planning, sustainment, sparing and repair, as well as a host of other functions will be shown as completely applicable to a perspective as a series of plan, make, source, deliver and return steps - The Supply Chain Council's SCOR steps.

Finally but more importantly, this paper addresses how SCM is more than just low costs and lean efficiency; it shows how the aerospace industry can shape and respond to changes in demand pressures while allowing for insertion of new technology and processes without new congressional funding appropriations or departmental reorganization. What we are addressing is a representation and conscious effort to manage the many layers of "logistical" activities from both the strategic and tactical approach. We have also determined that this framework

$$
-2 \text { - }
$$

Presented at the AIAA Space 2006 Conference, San Jose, California

This material is declared a work of the U.S. Government and is not subject to copyright protection in the United States. 
can be accomplished within proper interpretation of the existing NASA Policy Directives (NPD) for Procurement, Program Management and Logistics. We will also redefine the Supply Chain Councils' five step process but with a NASA-wide deployment strategy. Success with this endeavor will require process improvement, technology, money and people. The efficiencies gained will result from integration, collaboration and planning. Efficient, agile and cost effective will become the standard.

\section{Understanding Launch and Landing Costs}

In terms of process definition, drivers of these, relationships to fixed and variable costs, relationships to flight and ground system design and potential business processes and Information Technology (IT) systems changes that could improve these functions, requires a new Product Lifecycle and Supply Chain modeling and simulation approach and capability. Such an approach of necessity is focused on understanding multi-attribute influence relationships during the life of the Program that can support multi-attribute decision making. In effect, the decision making space is enriched, as a SCM perspective discovers and then opens up areas for improvement that are traditionally taken as a given, or accounted for as business as usual. As an example, consider the following question: What is the change in launch and landing ground operations if the new Crew Exploration Vehicle ("Orion") service module uses one propellant vs. another. Traditionally such a question is answered by looking only at those portions of the analysis tree or influences that derive from such a technical change. Such an analysis assumes "business as usual and static funding levels" for all indirect costs, and enabling functions, as no such capability currently exists to analyze "what if" factors related to the content of those indirect or enabling functions. The largest percentage of the Launch and Landing indirect costs would include KSC Ground Operations, Infrastructure and Flight Element Logistics. See Figure 1.

\section{Direct and Indirect Procurement Core Activities and Cost Percentage of Total}
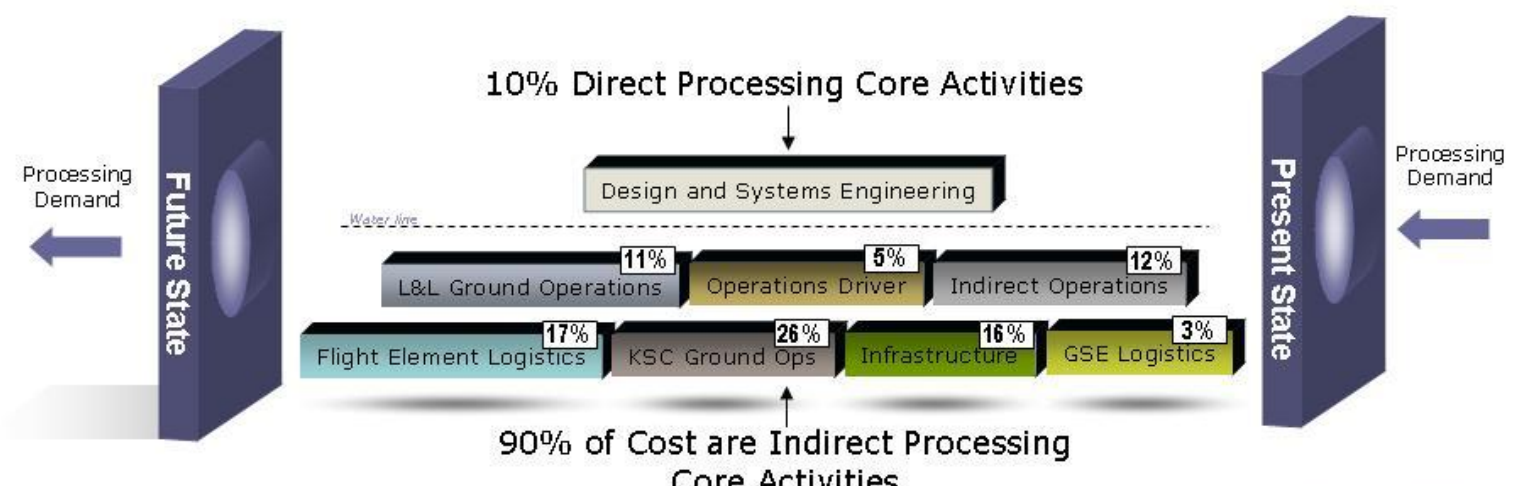

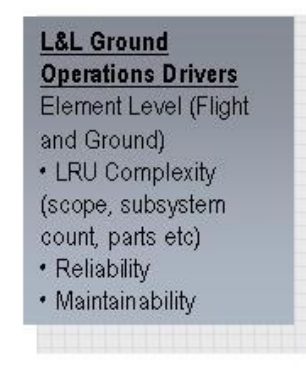

Figure 1
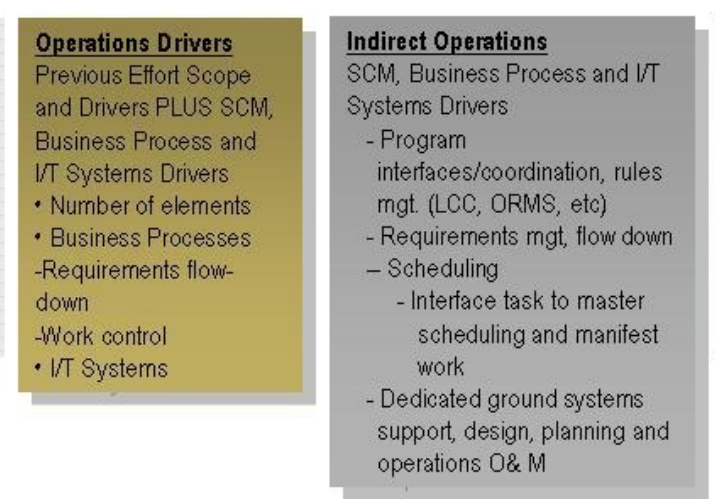
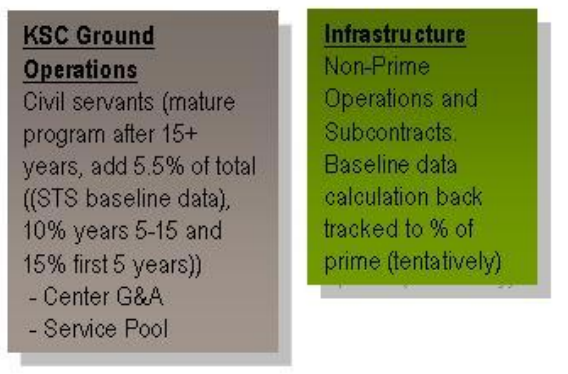

Fig.1: Breakdown of direct and indirect processing costs for Launch and Landing operations

Alternately, besides changing a propellant, one can also change the business processes that support readying that system. Factors would of necessity address:

1) Best practices

2) Process re-engineering

$-3-$

Presented at the AIAA Space 2006 Conference, San Jose, California

This material is declared a work of the U.S. Government and is not subject to copyright protection in the United States. 
3) Information flows

4) IT systems

5) Material flows

6) Budget Appropriations

The result of the prior influence relationships is a definition of plausible actions that can be pursued further as most promising. Consider another example the functions inherent in indirect prime contractor functions at a launch site such as the Kennedy Space Center. The Supply Chain Management, Business Process and IT Systems employed drive this category of indirect prime contractor functions which include:

1) Program interfaces / coordination, rules management (LCC, Orbiter Maintenance Requirements Schedule (ORMSD), etc)

2) Requirements management and flow-down

3) Generate work documents

4) Configuration management

a. Documentation, work authorization, tracking

5) Work control

6) Scheduling

a. Interface tasks into master scheduling and manifest and schedule daily work

7) Dedicated ground systems support, design, planning, and operations and maintenance (O\&M).

As the prior categories of indirect costs comprise $50 \%$ of Launch and Landing prime contractor costs, and to the degree the size of theses functions rely on the business processes and information systems that are at the heart of these functions, and to the degree that these costs are independent of the product lifecycle, in this case flight and ground system design, then a quantified understanding of how SCM improvements affect such a category is crucial to improvements in overall space transportation systems costs and productivity. The prior area does not even include the actual "deliver" component of logistics by the prime contractor, which is accounted for separately - another area ripe for the application of advanced SCM practices.

Additionally, the NASA portion of the supply chain, here from the perspective as customer "sourcing" (rather than the contractor category of "delivering" using the SCOR framework liberally) has many of the same indirect or enabling functions that merit analyzing. To what degree are these functions independent of the flight and ground system product design? It is estimated that a category of costs traditionally referred to as G\&A (General and Administrative) and Service Pools, what the Agency now calls Center Management and Operations, or CMO to include Safety and Mission Assurance (S\&MA) in FY08, constitute up to \$2.5 Billion dollars of the annual NASA budget (less S\&MA). At just NASA's Kennedy Space Center alone, the amount may be some \$300M a year of content associated with information and material flows such as finance, procurement, and assorted initiatives associated with the infrastructure that flow information and material to enable the more visible activity of launches. Once again, modeling the content as supply chain functions, such as within a SCOR framework, lays the ground to attach an action, (such as a specific best practice or a specific business process change) to a measurable thing such as cost or turnaround of a processes product.

Lastly, an integrated approach applying SCM factors as well as modeling the actual product parameters, flight and ground systems design, accepts that the influence relationships even at a macro-level of an entire operation such as NASA KSC Launch and Landing, are a rich tapestry of an inter-connected thread of influences as shown in Figure 2. 


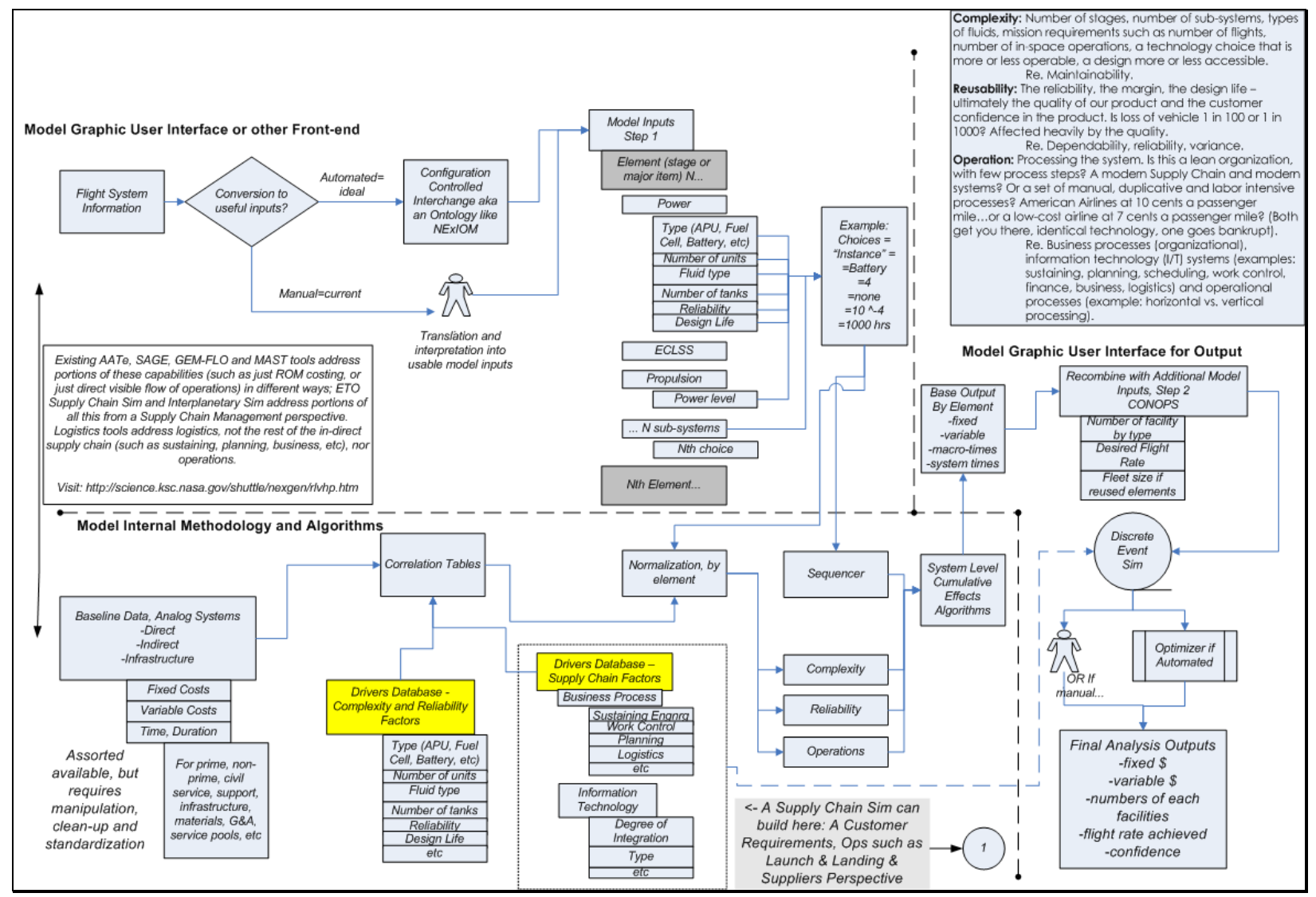

Fig.2: Supply Chain influence diagram

These influences must be wrapped together, within frameworks that seek to present simple but powerful relationships about a complex system and its phase of the system lifecycle. It must answer questions of how to build a system for supportability, iterate on design parameters in a multi-dimensional trade space to achieve a specific behavior and support characteristic and do it in a distributed interactive virtual environment. As an example, we can use the correlated relationship of traditional cost patterns to a systems lifecycle (Figure 3).

\section{Product Lifecycle to Cost Trend Analysis}

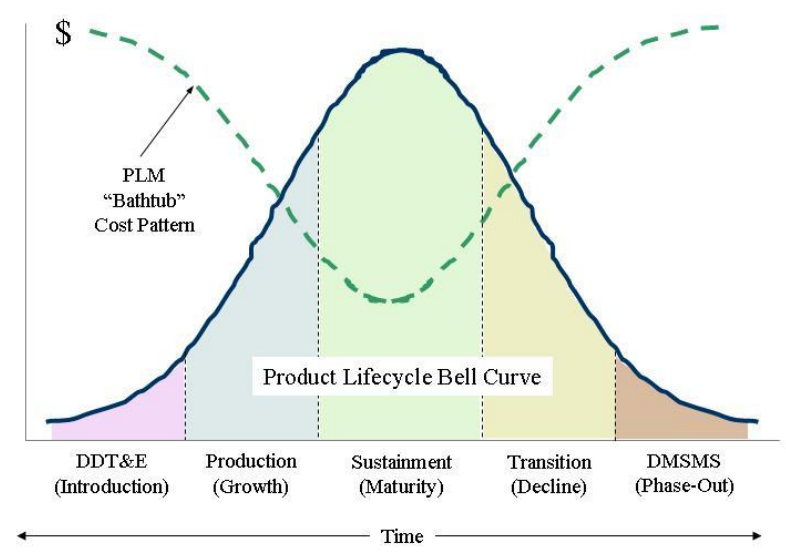

Fig. 3: Product Lifecycle cost "bellcurve" model III. Earth-to-Orbit Supply Chain Simulation Modeling

-5 -

Presented at the AIAA Space 2006 Conference, San Jose, California

This material is declared a work of the U.S. Government and is not subject to copyright protection in the United States. 
We have so far addressed tactical approaches so now let's focus on the strategic. Strategic analysis capabilities can and are being developed to influence future directions for NASA space transportation systems developments and operations, to assist decision making and to quantify the numerous inter-relationships described herein. The NASA Earth-to-Orbit Supply Chain Simulation for Exploration is a project in work sponsored by the NASA Explorations Systems Mission Directorate as part of the Integrated Modeling and Simulation portfolio of products.

Why Supply Chain Management at NASA and why now? Because SCM offers a powerful end-to-end perspective and practice very applicable to NASA needs for developing Exploration supply chains that are flexible, responsive and sustainable.

Borrowing a definition from Wikipedia, "Exploration is the act of searching or traveling for the purpose of discovery, e.g. of unknown regions, including space (space exploration), or oil, gas, coal, ores, caves, water (also known as prospecting), or information." In the case of NASA our explorers will require extended support systems of material and information as the uniqueness of the endeavor will define an extended supply chain on Earth up to a Spaceport node, including its processes and the final launch point node on the ground. Once in space, the chain will extend outwards with information and material flows. Eventually material will flow in both directions, with crew returning, hardware being delivered to planetary outposts, and materials such as rocks and specimens, being returned to Earth from other Planets. A SCM analysis capability is strategic as it:

1) Is where most of the costs will reside for future space transportation systems if trends oberserved in the past will persist in the future, namely: most costs are bound up in operations.

2) Is an analytical capability that is possible now, due to advances in both handling knowledge and in simulation techniques

3) Is a technique that is adaptable to new technology in the product lines (e.g. future block upgrades of CEV)

4) Is adaptable at the Enterprise / macro-level view from requirements to launch execution

5) Can represent systems that have both information and material flows, especially suitable to lower volume aerospace applications

6) Is life-cycle focused

We define an Exploration Supply Chain as:

"The integration of NASA centers, facilities, third party enterprises and international partners, orbital entities, space locations, and space carriers that network/partner together to plan, execute, and enable an Exploration mission that will deliver an Exploration product (crew, supplies, data, information, knowledge, physical samples) and to provide the after delivery support, services, and returns that may be requested by the customer." Notionally, an abstracted visual representation of such a system is shown in Fig. 4:

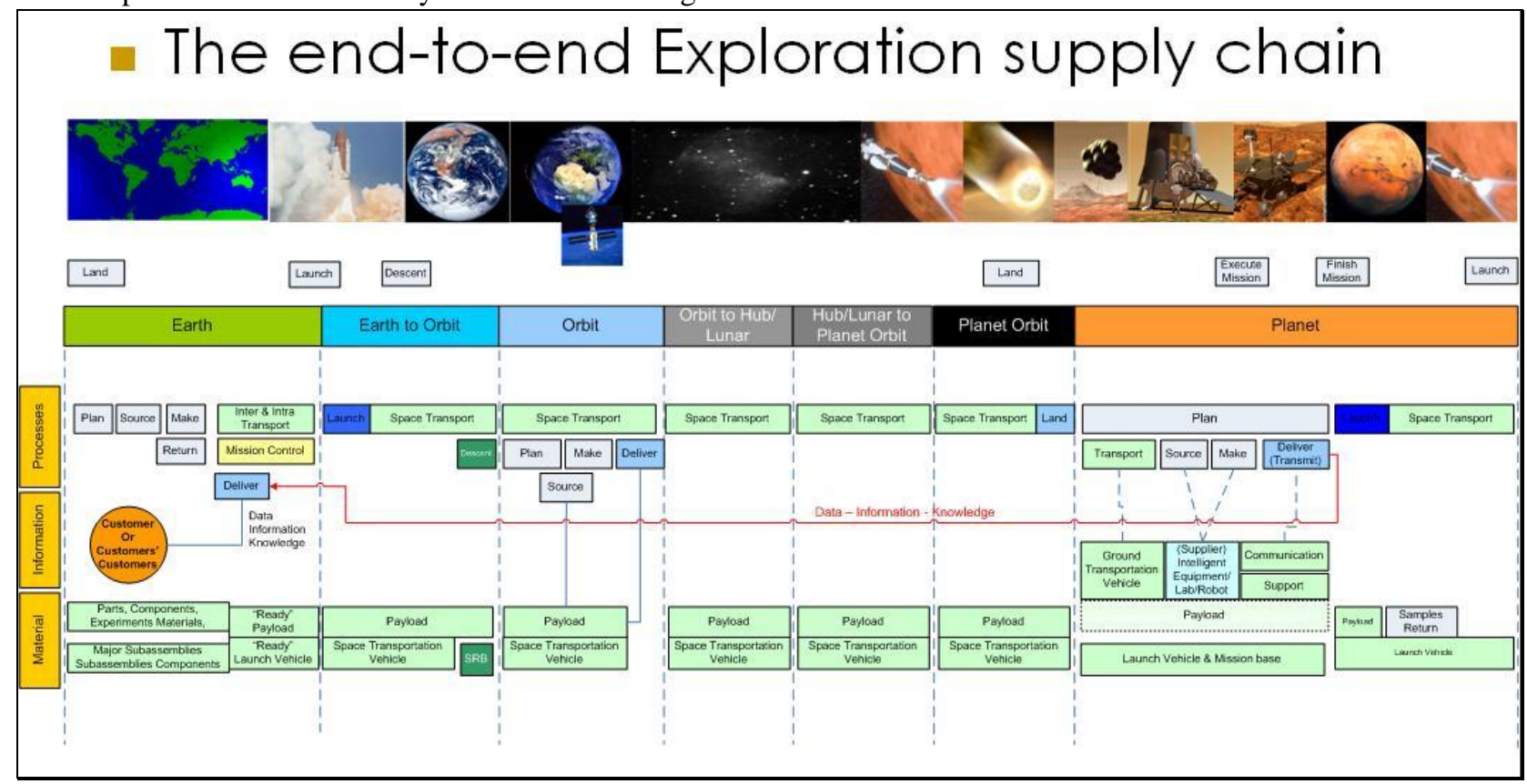

Fig. 4: Asbtracted visualization of the end-to-end space exploration supply chain with material flows, information flows and main processes on Earth, in Space and at Planetary locations.

$$
-6 \text { - }
$$

Presented at the AIAA Space 2006 Conference, San Jose, California

This material is declared a work of the U.S. Government and is not subject to copyright protection in the United States. 
Such a capability is developing using the Supply Chain Council "SCOR" Model, the Supply Chain Operations Reference model. In this process the standard 5 processes of plan, source, make, deliver and return, and the more detailed sub-processes, are taken and the current NASA processes are mapped into these. Center's and contractors (especially prime contractors) become "functional units" as in a distributed business with numerous entities contributing sub-assemblies, information and value to steps leading to finished products. The process highlights redundancies, or duplication as well as choke-points once represented in a time-based discrete event simulation. In this case the product is a launch, but the actual product may more specifically be said to be a requirement that has been accomplished, as this may be the return of scientific information or planetary specimens, from the point of view that the transportation is incidental (odd as that may sound). To manage all the knowledge required, an ontology is being developed for such a simulation to be effective, as such a knowledge based approach circumvents issues which even sophisticated data-base approaches can not resolve.

As of this writing the initial Phase I of this project has been completed, addressing ontology, simulation and user interface development, minus the integration of these and the necessary depth in order to provide useful analysis. In Phase 2 of this project that is underway, the depth and the integration of all 3 aspects of the Earth-toOrbit simulation are being further developed so as to lead to a useful analysis capability in mid-2007.

\section{Interplanetary Supply Chain Simulation Modeling}

Sustainable space exploration, however, is impossible without appropriate SCM beyond Earth. Unlike Apollo, future exploration will rely on a complex supply-chain network on the ground and in space. The primary goal of the NASA-funded project Interplanetary Supply Chain Management and Logistics Architectures (ISCM\&LA) is to develop a comprehensive SCM framework and planning tool for space-logistics, focusing on the in space portion of the supply chain. Four segments of this project include Terrestrial Supply Chain Analogies, Space Logistics Network Analysis, and Exploration Demand-Supply Modeling with Uncertainty, and Interplanetary Supply Chain Architecture Trade Studies. More detailed papers, reports and information about the project are available at: http://spacelogistics.mit.edu

\section{A. Terrestrial Supply Chain Analogies and Space Logistics Lessons Learned}

The Terrestrial Supply Chain Analogies segment of this project investigated and contrasted lessons learned from SCM in (i) major industries specialized in "low-quantity", capital-intensive products, (ii) long-range military operations such as aircraft and naval-submarine logistics, and (iii) supply-chains for operations in remote environments. For the remote environments effort, an expedition to the Haughton Mars Project (HMP) in the Canadian high Arctic (75N 90W) was undertaken to obtain first hand knowledge of logistics commodity \& information flow in a remote environment ${ }^{3}$. In supporting the logistics analysis of the HMP, the following was accomplished:

1) Development and validation of classes of supply items for applicability to space logistics

2) Development of a nodal model of transportation modes to assess the unit cost, time and availability, and the bulk-density and criticality of goods transported

3) Experiment with Bar Code and Radio Frequency Identification (ID) methods of supply tracking and management

A full report of the HMP expedition and a companion report on space logistics lessons learned are published in NASA Technical Publications (TP-2006-214196, Haughton-Mars Project Expedition 2005 and TP-2006-214203, Logistics Lessons Learned in NASA Space Flight). The top seven lessons learned from past manned spaceflight programs (Spacelab, Shuttle, ISS, ...) in space logistics are:

1) Incorporating stowage requirements in vehicle design specifications

2) Requiring a common logistics/inventory system across multiple organizations

3) The logistics information system should intuitively accommodate the movement of parent-child relationships

4) Commonality is a prime consideration for all vehicles, systems, components, and software

5) Design for maintenance is a primary consideration in reducing the logistics footprint

6) Plan for and apply standards in system development

7) Include return logistics in the design/specification

\section{B. Space Logistics network analysis (SpaceNet)}

The space logistics network model contains nodes in the Earth-Moon-Mars system, including Lagrangian points and expected landing-exploration sites, and arcs representing crew/cargo and vehicle element flows between the nodes. The crew and cargo are manifested into individual flights. With this model, testing various scenarios is possible to determine the benefits of different logistics philosophies from pre-deployment to carry-along to re-

$$
-7 \text { - }
$$

Presented at the AIAA Space 2006 Conference, San Jose, California

This material is declared a work of the U.S. Government and is not subject to copyright protection in the United States. 
supply. Optimizing the right mix of these complementary strategies is the most important aspect of space exploration logistics from a space-based (as opposed to ground-based) perspective. One unique point differentiating terrestrial from space nodal networks is that the in-space nodes are in constant relative motion to one another, creating time and energy dependencies in the network. Meeting critical demand requirements calls for considering these dependencies in the supply flow analysis. To this end, the SpaceNet discrete event simulation model is in development. (see Fig.. 5).

SpaceNet ${ }^{4}$ is a demand driven discrete event simulation and optimization software for space logistics. Currently, version 1.2 is under development in a Matlab/Excel-based environment. The main components of SpaceNet are:

- Movement or shipment of people, cargo, and vehicles

- Demand by supply class

- Information architecture

- Simulation

- Optimization

The challenge that SpaceNet addresses is to integrate models for shipment strategies and demand with the information architecture, then wrap these components together under a simulation layer, and incorporate some degree of optimization. The key is the recognition that - similar to terrestrial SCM - the space exploration logistics scenarios are largely demand-driven. When demand 'arises' at a lunar surface base, shipments must be allocated to fill it. Demand, in turn, is determined by the mission scenario - the length and location of surface stay, type of interplanetary transfer, number of astronauts, science mission, etc. By allowing demand to drive shipments, then selecting various shipment strategies, a large number of approaches can be tested for the same mission scenario. A schematic overview of the model is shown in Figure 5.

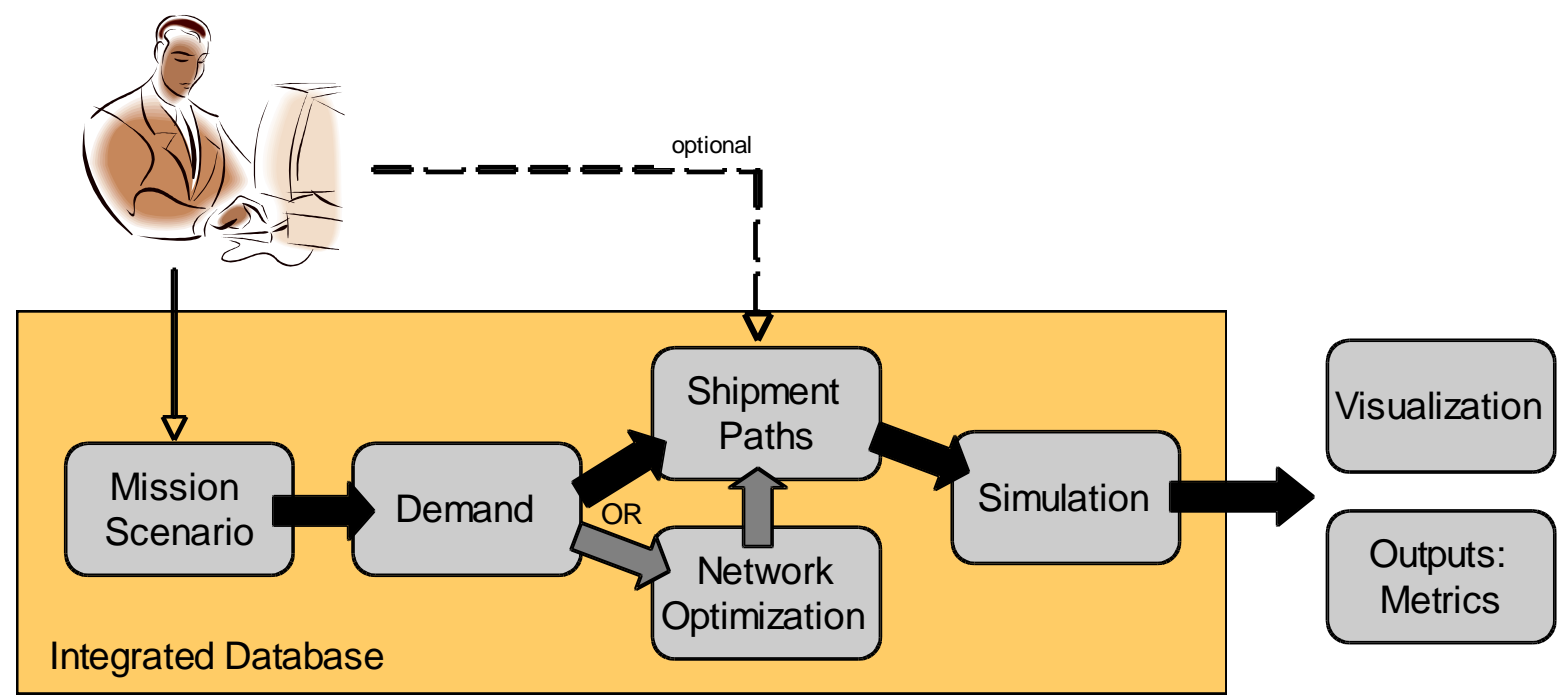

Fig. 5: Schematic Overview of SpaceNet Model Architecture

The demand levels are determined by the mission scenario, which is input by the user. The next step is to model various shipment strategies. This is quite a complex problem, because the decision space is very large and often difficult to describe. The solution is to borrow from the terrestrial logistics field and model the transportation options as a series of nodes and arcs. Nodes represent locations such as Kennedy Space Center (KSC) or LEO, while arcs represent the trajectories between nodes, such as chemical rocket trajectories from LEO to EM-L1, launch trajectories from the lunar surface to LLO, or even driving routes from a Martian base to a science target. In addition, astrophysical constraints dictate a time-dependence in the cost (in terms of propellant) of traveling each arc, which does not exist in most terrestrial cases. A time-expanded network is therefore utilized. With this modeling solution, the cost of any given logistics solution can be modeled by summing the costs of traveling arcs and waiting at nodes. Any shipment strategy can be modeled by choosing various paths through the network (Fig. 6).

$-8-$

Presented at the AIAA Space 2006 Conference, San Jose, California

This material is declared a work of the U.S. Government and is not subject to copyright protection in the United States. 


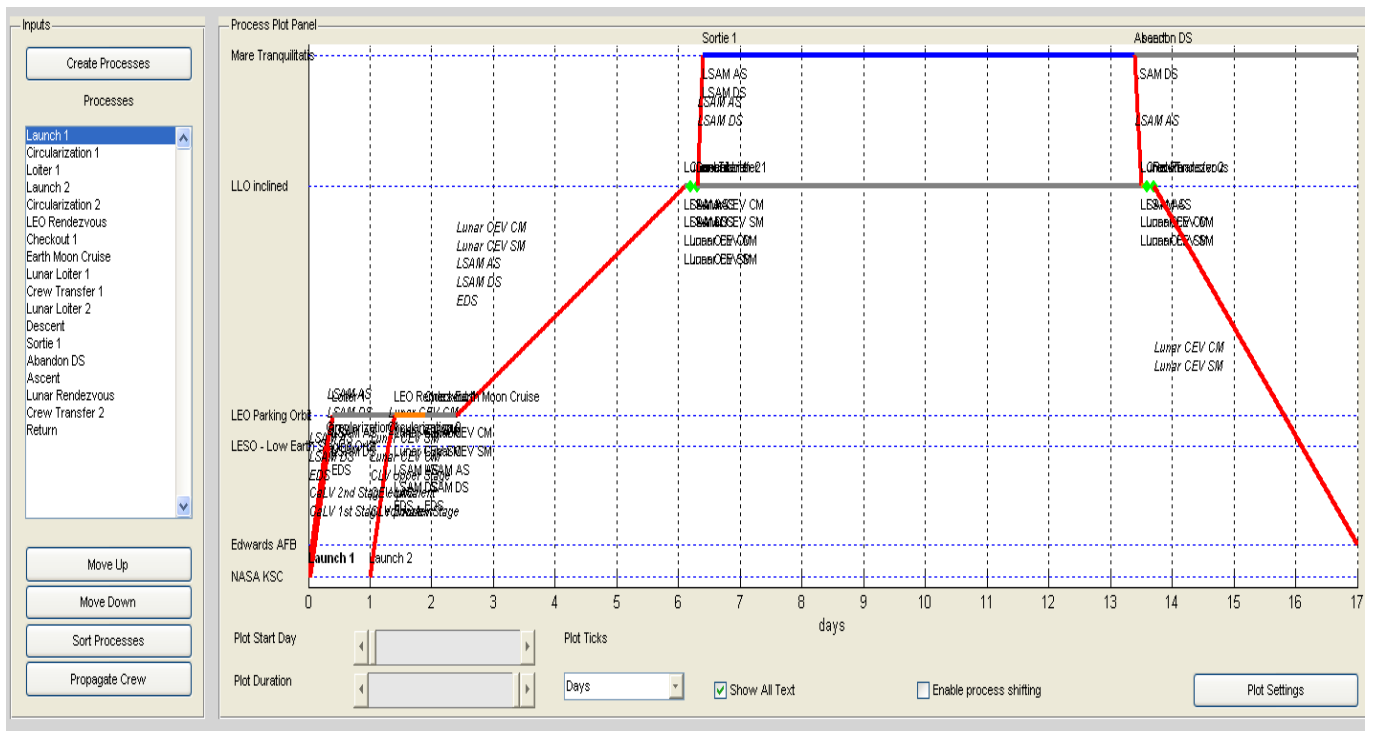

Fig. 6: Baseline NASA Constellation Lunar Sortie scenario modeled in SpaceNet v1.2. The $x$-axis shows time in units of Earth days, the y-axis shows various Earth, Space and Lunar nodes. Processes modeled include: transporting, waiting, exploring, docking/undocking and transferring crew and cargo from one element (vehicle) to another.

The information architecture takes the form of a relational database incorporating all aspects of the model: the input mission scenario, demand models, nodes and arcs, and output data (details of the relational database are available in a separate paper). All software modules interact with the same database, ensuring a consistent information architecture for the diverse functions of the model.

Optimization is incorporated at the level of the transportation network. Given inputs of demand at various nodes and times, the optimization chooses the best shipment path through the network, based on the available vehicles, nodes, and arcs. The shipment paths can also be chosen manually, in order to enable trade studies. For example, by choosing shipment paths which force all supplies to travel well before the crew, pre-positioning strategies can be evaluated.

Finally, the simulation layer takes all the data generated by other modules: the demand levels, shipment paths, vehicles utilized, etc. and simulates the logistics scenario in Matlab. The simulation ensures that demand levels are in fact met by the shipment strategy chosen, that demand generated along arcs (e.g. crew traveling to Mars) is satisfied, that vehicles carry enough fuel for the journey, etc.. The simulation also incorporates a visualization of the network and the shipment strategy, which is a valuable tool for developing an intuitive understanding of various logistics solutions.

In Apollo-style (sortie) missions, where all supplies are carried on-board for short duration missions, essentially all logistics support exists on the ground. This is a very truncated supply chain. On the other hand, for long duration missions (lunar outposts), the supply chain extends into space and to the point of exploration on the surface of the moon/Mars or on the ISS. The (simple) nodal perspective of the growth in the space supply chain shows the increase in complexity that demands careful planning (Fig. 7). SpaceNet is designed to model these networks and easily accommodate the addition of nodes and vehicles to support the analysis of the evolving exploration era supply chain. The user inputs supply demand, transportation capability and schedules, and nodal parameters to obtain various measures of effectiveness pertaining to satisfaction of exploration mission requirements.

-9 -

Presented at the AIAA Space 2006 Conference, San Jose, California

This material is declared a work of the U.S. Government and is not subject to copyright protection in the United States. 


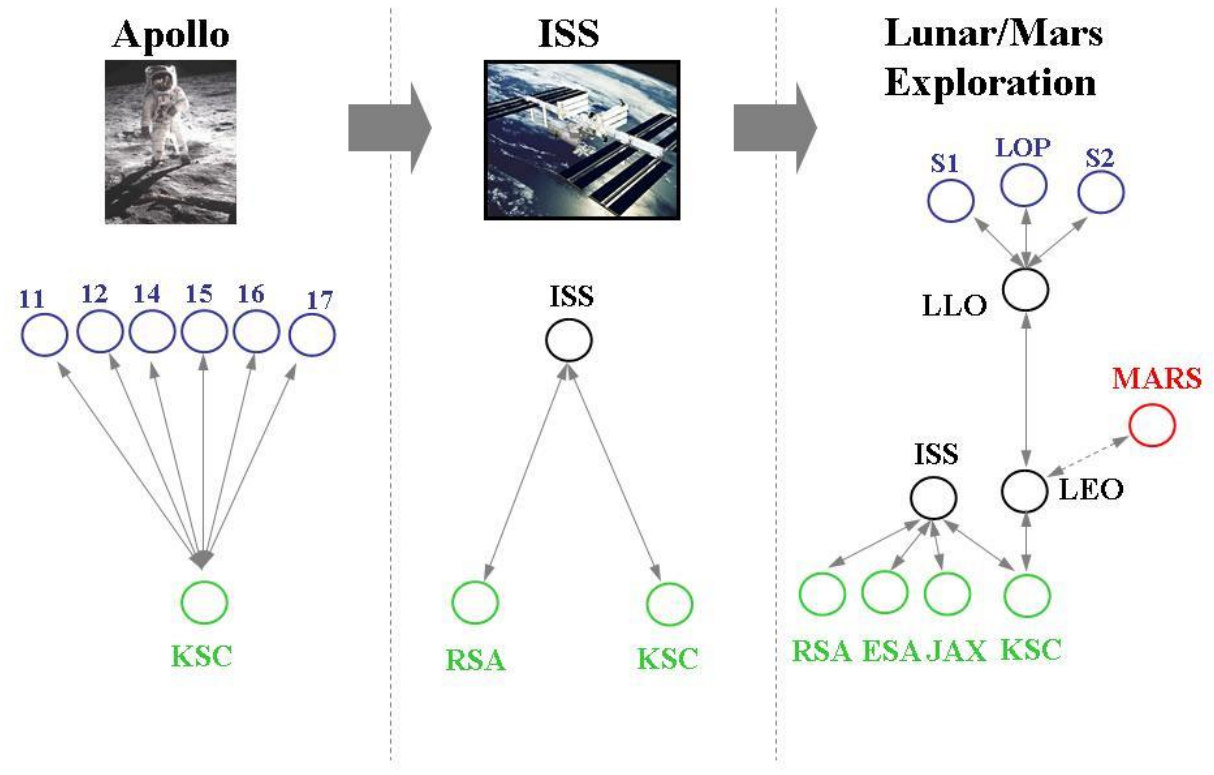

Fig. 7: Evolution of space supply chains from Apollo to the present (ISS) and future

Uncertainties in supply and demand of the space logistics network, such as demand variations, changes in the cargo-mix, transportation costs, and unplanned supply-line interruptions, are important considerations when performing supply chain analyses, as well as storage and lifetime issues (degradation, obsolescence, cryo-boiloff) and consumption rates. Populating the supply-chain network model to run these various logistics scenarios, starting with CEV development and deployment (2010-2014), all the way to lunar sortie missions (2018-2020) and the buildup of a lunar outpost (2021-2023) allows critical analysis of supply chain effectiveness prior to implementation. SpaceNet incorporates 10 functional classes-of-supply (COS), including propellants, crew consumables, spares, and exploration and mobility equipment, for the analysis of exploration logistics, which were developed and validated during the terrestrial analogies and space logistics lessons learned segment of this project.

Incorporation of supply/demand uncertainties with the SpaceNet discrete event simulation model allows the execution trade studies to help answer questions with regard to launch and space vehicle assignment mix, location of ground facilities and in-space transfer points, and logistics and information architectures boundaries. Combining trade studies to analyze the support requirements of both the International Space Station (ISS) and lunar missions is crucial to flight planning of current and future vehicles.

\section{Collaborative Planning within the NASA Policy Guidelines}

A SCM operational architecture will stimulate improved project element collaboration, hardware demand planning, component production forecasting, workforce scheduling and Maintenance, Repair and Overhaul (MRO) hardware procurements throughout the life of NASA's next generation of Launch Vehicles. The functional architecture is designed to provide the Agency with a seamless information flow necessary to strengthen an efficient hardware spares and repair philosophy while maintaining a healthy supply base and a NASA-Center Repair Depot capability specifically chartered for conducting logical Failure Modes, Effects, and Criticality Analysis (FMECA) and rapid manufacturing capability for unanticipated hardware demand during a near-launch 60 day window.

The process known as collaborative planning, forecasting and replenishment (CPFR), to include MRO, is an integral part of the NASA supply chain. CPFR is the sharing of forecasts and related business information among business partners in the supply chain to enable automatic product replenishment. The CPFR technique takes the common supply chain network and shares asset information in very near real time, ultimately this could stimulate a collaborative dialogue between the different project elements and qualified suppliers but spearheaded by the NASA Program Office. The CPFR process falls well within with the guidelines of the Shuttle Programs NSTS 07700 Vol XII document, which defines the Space Shuttle logistics and supportability requirements and, depending upon interpretation of the existing but sometimes ambiguous NASA Policy Directives (NPD), specifically 7500.1a Program and Project Logistics Policy, 7120.5c Program and Project Management Processes and Requirements, NPD

$$
-10 \text { - }
$$

Presented at the AIAA Space 2006 Conference, San Jose, California

This material is declared a work of the U.S. Government and is not subject to copyright protection in the United States. 
4100.1a Supply Support and Materials Management and NPD 5900.1 Spare Parts Acquisition. The CPFR process allows for planning information with regards to asset demand forecasting, hardware production schedules and other demand generation requirements. It assists with planning the process using actual demand and hardware failure data and generating a plan for sourcing what SCOR calls (P2), manufacturing (P3), delivering (P4) and return (P5) of the correct asset. "Asset" defined in this case as property (real or personal), suppliers and people with a positive value. Ultimately, NASA and the contractor community will have a smooth flow of shared asset information across the agency to achieve a "world-class" response time with order fulfillment and to focus better on core planning and financial budgeting competencies.

Below is an example to further expand on what we mean when we refer to the sustainment NPD's being ambiguous and is our interpretation. Note that we focused on sections within the policies but highly recommend the reader go to the NASA main website and read these policies in full and develop an independent interpretation and conclusion.

\section{A. NPD 7500.1a Logistics Policy}

"Agency-funded programs and projects which produce reusable or maintainable flight or ground hardware will apply Integrated Logistic Support engineering and management concepts and techniques to all phases of the program or project cycle to ensure the new or upgraded system will be economically supported through its planned life"...

1) Responsibility Assistant Administrator for Infrastructure and Administration Management, compliance by Center Directors

2) Assessment The Policy leaves the Assistant Administrator responsible for "brick and mortar" infrastructure and facilities ultimately responsible for supporting and governing policy on "engineered systems" e.g. space flight hardware \& GSE "systems logistics". The implementation of the policy is not fully or completely implemented possibly because NPD $7120.5 \mathrm{c}$ creates lack of clarity by placing responsibility on the Program and Project Offices which 7500.1a also states that the "Programs and Projects will (an expectation, not a requirement) conduct Logistics Supportability Assessment regiment..." thus creating a lack of core capability within the top level agency officials for Flight and GSE Equipment

\section{B. NPD 7120.5c Program and Project Management}

"...describes the management system by which NASA shall formulate, approve, implement, and evaluate all programs and projects established for safe development and operation of aeronautical and space ground and flight systems and technologies."

1) Responsibility: Spans the NASA Management Chain; compliance by the Agency Program Management Council and Chief Engineer

2) Assessment: NASA Policy Requirement (NPR) 7120.5B state "the project office shall (a requirement) establish a logistics requirement per NPD 7500.1A to identify lifecycle cost drivers for design support..." The overall program requirements i.e. Sustainment/Logistics and Supply Chain are levied on the Program Office but the flexibility of the materials and information integration is "interdependent" of the projects. Project Office has the ultimate responsibility not the Program and in some cases delegated to the contractor.

\section{NPD 5900.1a NASA Spare Parts Acquisition}

"The Spare Parts Acquisition Policy establishes a uniform policy for the acquisition and provisioning of NASA spare parts. Program managers/Enterprise Associate Administrators have the overall responsibility for spare parts management for programs under their cognizance. Program managers are responsible for direction and management of spare parts required to support their assigned system...Logistics/program managers are responsible for establishing logistics support methodologies for systems..."

1) Responsibility: Procurement Office

2) Assessment: This NPR establishes a uniform policy for the acquisition and provisioning of NASA spare parts. Replenishment defined by this NPR means "the process of pricing, ordering, and stocking spare parts needed to maintain or repair a major system over its life based upon the initial provisioning list and usage patterns established during the initial provisioning period. Replenishment begins when the initial provisioning period ends. Either the Government or a designated contractor, where it has proven to be cost effective, may accomplish replenishment." However, NPD 4100.1a states "Maximize the use of outsourcing and trading partner inventories (e.g., Just-in-Time/JIT) as the primary method for stores, program, and standby stock material requirements. Material should not be warehoused at a Center unless there is no cost-effective alternative." This policy limits technology infusion later in the PLM as an alternate Diminishing Manufacturing Source and Material Shortages (DMSMS) mitigation path - assumes stock piling inventory and does not consider JIT for replenishment on reusable systems. Assumes systems

$$
-11 \text { - }
$$

Presented at the AIAA Space 2006 Conference, San Jose, California

This material is declared a work of the U.S. Government and is not subject to copyright protection in the United States. 
are nonexpendable with trailing repair and sparing philosophy to support inventory stockpile. More importantly it identifies either Program or Project or the Contractor to make a determination of LOT buys. Similarly, maverick procurement may occur when there are similar programs using the same product line leaving redundant procurement activity within NASA competing against the other project office and not negotiating one lot buy for the program instead of one lot buy for the project. This is further exacerbated by leaving ILS activities to the contractor thus leaving potential for an inflated price due to the addition of contractor SG\&A and profit to the final price.

\section{NPD 4100.1a Supply Support and Materials Management}

"Supply support and material management shall be structured to be responsive to customer requirements at minimum cost and demand on the NASA logistics infrastructure." "... This policy shall be incorporated in all contracts for onsite NASA material management/supply support."

1) Responsibility:_Assistant Administrator for Infrastructure and Corporate Management, compliance by Center Directors

2) Assessment: Combines institutional supply with flight, GSE and STE requirements but puts supply support and material management requirements in contracts under their purview. Center Directors are to appoint a supply and equipment management office (SEMO), an Inventory Adjustment Officer and responsible for establishing supply support and management of material requirements for their program/projects. Creates lack of clarity between NPD 7120.5C, NPR 7120 and NPD 7500.1a.

\section{E. NSTS 07700 Vol. XII Space Shuttle Logistics and Supportability Requirements}

Original document baseline April 1973, "The Manager, Space Shuttle Program (SSP) shall be responsible for developing and maintaining the Program Logistics requirements. The Space Shuttle Project Element Managers shall be responsible for developing, maintaining, and implementing logistics support to ensure compliance with the requirements of this document. The Manager, SSP Logistics shall be responsible for ensuring logistics integration across the Program."

1) Responsibility: SSP Program Office Logistics Manager

2) Assessment: NSTS 07700 contains several volumes providing program level requirements for the SSP. This volume provides requirements for a comprehensive logistics program to assure that flight hardware and ground systems are maintained to their design performance. The project elements of the SSP must establish logistics processes and systems to adhere to these requirements for maintenance, supply support, packaging, handling, storage, and transportation, and personnel training. These logistics activities are performed by each element; however, some elements apply them differently. Eg. the elements still in production, Reusable Solid Rocket Motor and External Tank, define logistics as that support provided only for hardware delivered to KSC, not to the production of flight hardware. Orbiter, Space Shuttle Main Engine, and Solid Rocket Booster apply them to the repair, maintenance, and overhaul of their hardware.

When inventory is a necessity at multiple logistic nodes and hardware sparing is the driver, the Agency could outsource the "busy work" associated with procurement of inventory after negotiations have taken place, and leave the spares and production forecasting responsibilities to NASA. This would also include the busy work associated with monitoring the repair activities/responsibilities to contracted partners but only with a tight contractual agreement or Contract Data Requirements List (CDRL) and link these "partners" on a more intimate level by integrating within the NASA SCM shared information network and other non-proprietary information and IT systems such as the NASA Integrated Enterprise Management Program and SAP R/3 Asset Management system. As an example, consider the following question: What is the impact to the supply base if the new Crew Exploration Vehicle Crew Capsule is considered a non-repairable item? What is the repair cost threshold associated with repair vs. buying new? What would be the hardware obsolescence mitigation path and how much would be the cost? These are questions best answered with a collaborated and data shared approach with Program Office oversight.

One could argue the point of taking the CPFR process further and integrating with the Defense Logistics Agency's emergent systems for rapid mobilization of manufacturing sources or what they call the Battlefield Backorder Breakout Initiative (B3I). B3I is a coalition of Defense purchasing activities and Integrated Manufacturing Networks (IMNs) that takes responsibility for determining best available solution including engineering/technical evaluation, failure analysis and production. This type of coalition, enabled by electronic data interchange and/or secure Web-based systems, could add to NASA's Value Chain and provide the visibility into such things as objective supplier viability and supplier liquidity within the NASA product line while at the same time, providing suppliers with advanced priority short-term demand requirements by NASA.

$-12-$

Presented at the AIAA Space 2006 Conference, San Jose, California

This material is declared a work of the U.S. Government and is not subject to copyright protection in the United States. 


\section{Supplier and Product Line Viability}

Total or impending loss of a supplier or product line, to include critical second tier sources, skill and/or raw material is due to a number of factors such as change in ownership or business strategy, decline in a companies financial liquidity, rapid change in product technology, foreign competition, U.S. environmental regulations and limited availability of raw materials. DMSMS or total loss of a supplier is a serious and costly impact to sustaining any program and can impact both the flight manifest and obligated Program Operating Plan budget due to unforeseen and unusual economic stresses on a supplier. A supplier solvency indicator could be expanded within the Earth-To-Orbit and Interplanetary SCM simulation models and could give forewarning by gathering and analyzing procurement data, opinion data, third-party financial information (if available), in addition to collecting internal logistics support analysis data e.g. Line Replaceable Unit Probability of Sufficiency (LRUPOS), mean-timebetween-failure, from the NASA project elements. This data would be collected by a Program Office or Agency SCM Center of Excellence. The result would be a collaboration of strategic capabilities but primarily a financial stability indicator model and supportability risk assessment of the supplier and subsystem. For prime suppliers, the key issues are increasing shareholder value by reducing excess manufacturing capacity, diversifying to global commercial markets, and retaining a technological lead over competitors. For sub-tier suppliers, the key challenge lies in sustaining design and production capabilities for certain key subsystems and components in the face of an increasingly shrinking market. However, designing an operations architecture that allows for new technology insertion will defuse the shrinking economic gains and diminishing marginal returns on older hardware and designs. Avionics, specifically the microelectronics are a good example of where "plug and play and throw away" works. Trying to maintain components that have at best an 18 month product lifecycle would be ludicrous. Hence, replace with a newer technology but one that meets the performance and in usual cases, exceeds the performance requirements. The culmination of this concept would be to provide NASA and the contractors with a working retention strategy with a standardized policy for daily monitoring of critical suppliers. The question regarding "monitoring" the health of the supplier base, focuses on the capability of all critical prime and sub-tier suppliers to provide engineering data and expertise, hardware, and the associated repair parts to adequately support the operational availability of the designed system especially during periods of program transition. Loss of a supplier is a serious issue for NASA and can impact sustainability of all systems at all stages of the system lifecycle as well as the obligated budgets due to unforeseen loss of a supplier.

Lessons learned to supplier viability:

A. No one program or project can be responsible for maintaining the industrial base for the entire agency. In this process the agency could;

1. Establish a central Supply Chain Management center of excellence for all Agency programs

2. Assess what level of supply base is critical for development.

3. Establish a critical or preferred supplier pool for all NASA.

4. Develop a strategy to encourage supplier consolidation to possibly include the DoD.

B. Utilize phased new program development as a strategy for vendor retention.

1. Evaluate and model program lifecycle maturity.

2. Use new program development and timing to eliminate program retention breaks.

3. Map a new programs supplier list to existing NASA programs.

C. Develop contracting strategies and contracting options to enable consistencies in supplier contracts.

1. Act as liaison with major prime contract candidates ways to gain synergies between programs and contracts.

D. Identify key competencies and shortfalls to support emerging technologies.

The linear business as usual "push" manufacturing model vs. a 21 st Century demand-centric "pull" model that proactively manages demand and uses stochastic optimization simulation methods for schedule variability as reflected in the diagram below (Fig. 8). The intent is a constant interplay between NASA and the suppliers. We can expect to:

1) Reduce costs by reducing inventory requirements and making better use of assets

2) Improve order fulfillment and on-time delivery

3) Increase responsiveness due to the increased demand and supply information visibility

4) Improve the ability to react to unplanned changes in demand.

$-13-$

Presented at the AIAA Space 2006 Conference, San Jose, California

This material is declared a work of the U.S. Government and is not subject to copyright protection in the United States. 
Present State

Linear, push manual practice

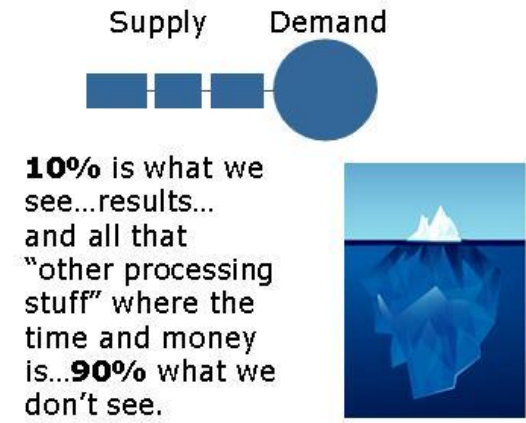

Accepting demand

New technology an exception

Deterministic optimization
Future State

Circular, self-renewing simulation model

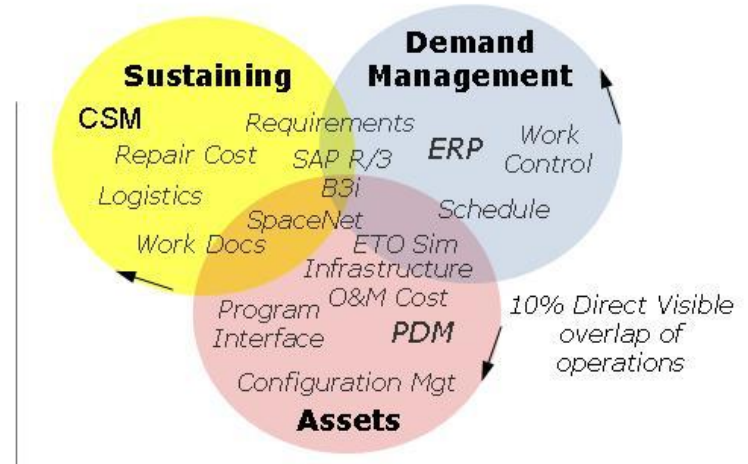

Shaping demand

Embedded technology insertion

Probabilistic planning optimization

Source: AMR Research, 2004

Fig. 8: Present and Future state of Space Logistics

The health of the supply base has an in-direct but significant relationship to the quality of the final product, the reliability of which is a factor in diminished potential market growth. That is, variance in aerospace products, as they are severely modified for unique uses, introduces reliability issues inversely proportional to the quantities being supplied. Where quantities are few, especially as in rocket engine/propulsion, power supplies, and mechanical system components, exacerbated at a system level, the reliability that can be expected diminishes rapidly. The aerospace response has traditionally been to create organizational overhead layers, the purpose of which often is to inspect what was not built in (to the product). A healthy supply base, increasing production units through commonality throughout aerospace applications, can offer improved reliability, eventually leading to systems maturity that can lead to market growth as competitors find a healthy supply base, with mature, better understood components, from which to develop and explore new systems.

\section{Standardization and Component Supplier Management}

A fundamental problem for most Logistics and Procurement Managers is part number and procurement duplication. "Conservative estimates of between $30 \%$ and $40 \%$ of a support contractors procurable spare parts are duplicates or have acceptable substitutes. With the annual carrying cost of between $\$ 4,500$ and $\$ 23,000$ per line item for the introduction of a new part number, duplicate part proliferation is an area of known cost exposure" ${ }^{\text {. }}$. Compound the fact that NASA as well as the DoD have to contend with Mil-Spec, Source Control Drawing and National Stock Number schemes, the cost could be even higher. In a "stove-pipe" organizational structure where the project offices act as independent agents, each part in turn may be purchased from a different qualified supplier and stocked with a different part numbering scheme. Not to mention the costs associated with certifying multiple sources and redundant purchase orders which will also result in poor asset utilization. "inaccurate demand forecasting and supply planning means that manufacturers carry excess inventory along their supply chain and suboptimize use of capital assets like plant equipment." ${ }^{, 6}$ Simply stated, the results are - too many parts and too many suppliers. At the day-to-day operational level, the cascading negative results include:

1) Inhibiting parts standardization

2) Discouraging design reuse

3) Increasing material and holding inventory costs

4) Creating excess / residual inventory 
5) Inflating purchasing administrative costs due to too many purchase orders for small quantities and too many suppliers

A common SCM architecture, to include Component Supplier Management (CSM), reduces maverick buying and will not jeopardize the ability to reduce operational recurring costs. CSM is advanced IT software applications used for parts classification, standardization and retrieval; as well as supplier (sourcing) management. Think of it as a way to develop and manage the Bill of Materials (BoM) throughout the system or program and product lifecycle. For a CSM system to operate in NASA's quality driven environment, the application must provide instant access to all partners in the Supply Chain and must also have the following characteristics:

1) Provide flexible part numbering classification schemes - without requiring intensive conversion efforts to a common or fixed scheme

2) Match the access and user needs of direct users, such as design engineering, procurement, logistics, and contracts.

3) Interpret part information in real time in any format.

4) Accommodate legacy parts data

5) Support creation and maintenance of standardized parts descriptions

6) Furnish data sheets on demand - integrate with on-line catalog information sources where possible

7) Supply multi-faceted analysis tools, including BoM unique/common parts analysis,; design cost impact in a "what if" simulation and evaluation of current part data base conditions

8) Generic transactions to update BoM files

9) Facilitate creation/maintenance of Preferred Parts List (PPL)

10) Integrate with application systems for CAD and Product Data Management (PDM). For decision support, supply chain information, such as inventory status from ERP and MRP systems must be readily available.

There are a number of cost benefits from implementing a CSM application in a common SCM architecture but one of the most significant is reducing duplicated parts and the costs associated with redundant sources of supply, by this we mean the certification cost associated with those suppliers and redundant contracting efforts.

\section{Conclusion and Recommendations}

The combination that has not existed before of awareness of NASA costs by function, of supply chain practices, techniques and technology such as simulation, and of the inter-relationships among factors that stretch from product dependent factors, such as a new space transportation system design, to supply chain system dependent factors, offers a historical opportunity to dramatically improve the cost, responsiveness, and safety/reliability for the Exploration task ahead of us.

Implementing a new practice within the Agency can be very difficult and time consuming. It is even more difficult in this case since supply chain is a new concept within the Agency, large number of supply chain practices, over 500 best practices in the SCOR model, and supply chain management requires cross-functional framework. Simulation - SCOR best practices - logistics support. Agency-wide SCM Solution - how do we get there from here? A five step process to implementing a SCM policy.

$\underline{\text { Step } 1}$ Make the business case. Evaluate sustainment and operational requirements and compare to existing processes and validate the change as value added to the Agency. Make the Sale to Suppliers. First comes the hard part. Supply chain automation is uniquely difficult because its complexity extends beyond the Agency and Contractor walls. We will need to change the way we work and so will the people from each supplier that we add to our network.

Step 2. Evaluate the financial and operational value to be achieved in terms of financial performance and operational performance characteristics such as cycle time, quality and service level attainment. Use modeling tools to simulate end-state financial statements and operational performance criteria. Wean the Employees off the Phone, Fax and email. Selling a supply chain concept is difficult on the outside and it isn't much easier inside. Operations people are accustomed to dealing with meetings, phone calls and work authorization documents and will most likely want to keep it that way. If we can't convince people that using the SAP R/3 software will be worth their time, they will easily find ways to work around it. ERP at least erases the old ways of working by blotting out legacy software systems. Supply chain software is less militant. We cannot disconnect the telephones and fax machines just because we have a supply chain application in place.

Step 3 Prepare for Bad Information. - At First there is a diabolical twist to the quest for supply chain process acceptance among the industry. New supply chain systems process data as they are programmed to do, but the technology cannot absorb the Agency's or contractor's history and processes in the first few months after an implementation. IEMP forecasters and planners need to understand that the first bits of information they get from a

$-15-$

Presented at the AIAA Space 2006 Conference, San Jose, California

This material is declared a work of the U.S. Government and is not subject to copyright protection in the United States. 
system might need some tweaking. If they are not warned about the system's initial naiveté, they will think it is useless.

Step 4 Make and enable the Supply Chain Connection to ERP project. You have probably heard that installing supply chain software is the natural next step after finishing an ERP project. Indeed, the two serve each other well. ERP captures all the product, finance and asset inventory information that supply chain applications need to predict demand and optimize the flow of material and information through the chain. Unfortunately, that symbiotic relationship does not translate into an easy integration between the two different systems. In all likelihood, our new IEMP AM (asset management) implementation will not interface cleanly with other current ERP systems.

Step 5 Enhance cross functional activity by defusing functional warfare within the NASA culture. Supply chain software projects bring CIO's and CFO's into direct conflict with the people who run the PP\&E day to day.

In addition to these steps, we can also begin to formulate a supply chain vision and strategy based on organizational aptitude and enabling technologies. "This strategy should include the following key steps;

$\underline{\text { Step } 6}$ Identify the Agency's core supply chain differentiators and capabilities, and assess current performance. partners.

Step 7 Determine which functions could be better performed by a partner, and begin to identify these

Step 8 Define the supply chain process components and the needs for organizational reconstruction.

$\underline{\text { Step } 9}$ Define the measurement framework, which is aligned with business objectives and goals. Set targets and thresholds for the key supply chain performance indicators.

Step 10 Define the real time information and connectivity vision, including an open- and-service-based technology architecture, required to support the vision". ${ }^{7}$

The Agency must be able to support multiple types of simultaneous activities. "Aerospace firms must become proficient at service execution and spare parts fulfillment. ...Companies need to augment ERP in areas such as sophisticated spare-parts planning, complex overhaul operations, technical documentation and automated condition monitoring." "A supply chain initiative should be pursued to better understand opportunities and define better ways of doing business. Such an initiative should be based on established Business Process Reengineering (BPR) and IT that are widely employed in the private sector. Improvements in SCM would address the areas and the interactions among Integrated Logistics Concepts, material and information flows, requirements management systems, work control and verification, ground process scheduling, program-level manifesting, corrective action systems, improvement systems, data management systems, sustaining and technical support, procurement and financial systems. Together, BPR and IT advances and an improved integration of the host of other common network operations and enabling functions, an initiative looking across all supply chain functions, may offer significant opportunities for improvement that must be quantified and defined." high-volume, consumer demand driven SCM disciplines of the commercial industry to a low-volume, schedule and quality driven Aerospace environment is also vital based on two simple words - human mortality. A schedule delay with today's Space Shuttle Program simply means increased day-to-day cost and that launch would be scrubbed for the day to try again at the next launch window. Schedule delays with a Lunar or Mars Outpost could mean a catastrophic life event based on the fact that at this point in time, there are basic human needs we must source from Earth e.g. water, oxygen, food and they must be delivered - on time, every time! This becomes especially crucial as human exploration moves further from Low-Earth-Orbit, as with the current Space Station, to operating logistics nodes that are Lunar based and beyond.

\section{References}

\footnotetext{
${ }^{1}$ Murphy, Charlie, Sealing, Scott, "Supply Chain Management and Integrated Logistics Support Considerations for Exploration,” United Space Alliance, May 2004

${ }^{2}$ Ellram, Lisa M. and Martha C. Cooper, "Supply Chain Management, Partnership, and the Shipper - Third Party Relationship," The International Journal of Logistics Management, Vol. 1 No. 2 (1990), pp. 1-10.

${ }^{3}$ O. de Weck and D. Simchi-Levi, "Haughton-Mars Project Expedition 2005", Final Report, MIT, NASA Kennedy Space Center, NASA Report NASA/TP-2006-214196, January 2006

${ }^{4}$ E. Gralla, S. Shull, O.de Weck, G. Lee and R. Shishko, “A Modeling Framework for Interplanetary Supply Chains", AIAA-2006-7229, Space 2006, September 19-21, 2006

${ }^{5}$ Aberdeen Group, “Component \& Supplier Management: Saving Time and Money Part by Part,"URL: http://www.i2.com/assets/pdf/PDS_csm_v61_pds7203 0404.pdf\#search=\%22\%E2\%80\%9CComponent\%20\%26\% 20Supplier\%20Management $\% 3 \mathrm{~A} \% 20$ Saving $\% 20$ Time\%20and\%20Money $\% 20 \mathrm{Part} \% 20 \mathrm{by} \% 20 \mathrm{Part} \% 2 \mathrm{C} \% \mathrm{E} 2 \% 80 \%$ 9D\%20Aberdeen\%20Group $\% 2 \mathrm{C} \% 20 \% 22$ Cited March, 2002
} 
${ }^{6}$ Radjou, Navi, “The Defense Contractors' Supply Chain Imperative, ” Forrester Research Brief Series, URL: http://www.forrester.com/ER/Research/Brief/Excerpt/0,1317,16196,00.html Cited August, 2003

${ }^{7}$ Lavacca, John, Bunyan, John and Cross, Gary, IBM Business Consulting Services "Transforming your supply chain to on demand: Competitive advantage or competitive necessity?,” URL: http://www-

1.ibm.com/services/us/index.wss/ibvstudy/imc/a1000510?cntxtId=a1000065 Cited March, 2003

${ }^{8}$ Bob Parker, AMR Research,. “Aerospace and Defense Industry. Outlook: Lifecycle Value Stream. Must Drive IT Investment,", URL: http://www.sap.com/industries/aero-

defense/pdf/BWP_SAP_A\&D_Maint_Repair_Overhaul.pdf\#search=\%22Aerospace\%20and\%20Defense \%20Industr y\%20Outlook\%3A\%20Lifecycle\%20Value\%20Stream\%20Must\%20Drive\%20IT\%20Investment\%2C\%E2\%80\%9 D\%20AMR\%20Research\%20\%22 August 16, 2004

${ }^{9}$ Stanley, Doug, NASA. “Exploration Systems Architecture Study (ESAS) Final Report, ” URL: http://www.nasa.gov/mission_pages/exploration/news/ESAS_report.html Cited July, 2005 